\title{
El hospital medieval de Pena Godón, una ventana al pasado de un despoblado olvidado en el Camino Francés a Compostela ${ }^{1}$
}

\author{
Rosario Valdés Blanco-Rajoy² \\ Recibido: 18 de novembro de 2015 / Aceptado: 28 de setembro de 2016
}

Resumen. Las claves que explican la evolución del lugar de Pena Godón son las mismas que explican la historia de los monasterios y encomiendas de las distintas ordenes religiosas y militares que se establecieron en estos parajes, su relación con la nobleza y el papel que conjuntamente desempeñaron como titulares de la propiedad de la tierra en el sistema de explotación agraria, y la incidencia que todo ello tuvo sobre la vida del campesinado. Son también las mismas claves que contribuyen a explicar el paisaje del tramo del Camino Francés donde se localiza este asentamiento, la historia de los establecimientos hospitalarios que se alzaron sobre sus márgenes y la de las personas e instituciones que los fundaron y gestionaron.

Palabras clave: Galicia; Camino Francés; hospitales de peregrinos; propiedad; nobleza; órdenes religiosas.

\section{[gl] O hospital medieval de Pena Godón, unha xanela ao pasado dun despoboado esquecido no Camiño Francés a Compostela}

Resumo. As claves que explican a evolución do lugar de Pena Godón son as mesmas que explican a historia dos mosteiros e encomendas das distintas ordes relixiosas e militares que se estableceron nestas paraxes, a súa relación coa nobreza e o papel desempeñado en conxunto como titulares da terra no sistema de explotación agraria, e o impacto que todo isto tivo sobre a vida do campesiñado. Son tamén as mesmas claves que axudan a explicar a paisaxe do tramo do Camiño Francés onde se localiza este asentamento, a historia dos hospitais que se levantaron nas súas marxes e das persoas e institucións que os fundaron e xestionaron.

Palabras chave: Galicia; Camiño Francés; hospitais de peregrinos; propiedade; nobreza; ordes relixiosas.

\section{[en] The Medieval Hospital of Pena Godón: A Glimpse at a Long Forgotten Place in the French Way of Saint James}

\begin{abstract}
The key points to the historical evolution of Pena Godón are identical to those that mark the history of monasteries and of various religious and military authorities that settled in the area. They also reflect the relationship of these orders with the nobility, the role played as joint landholders in a system of agrarian exploitation and the impact of all this on the peasants' way of life. These points also help explain the evolution of the landscape in this part of the French Way where the settlement was located, the history of its hospitals and the people and the institutions that founded and managed them.

Keywords: Galicia; French Way of Saint James; Pilgrims’ Hospitals; Property; Nobility; Religious Orders.

Sumario. 1. Introducción. 2. Pena Godón en el tramo del Camino Francés de Portomarín a Palas de Rei (Lugo). 3. La heredad de Vilar de Couso. 3.1. El casal y el hospital medieval de Pena Godón. 3.2. Evolución posterior y abandono final: el lugar de la Magdalena en la Edad Moderna. 4. Conclusiones. 5. Referencias bibliográficas.
\end{abstract}

Como citar: Valdés Blanco-Rajoy, R. (2016): "El hospital medieval de Pena Godón, una ventana al pasado de un despoblado olvidado en el Camino Francés a Compostela”, en Madrygal. Revista de Estudios Gallegos 19, 203-216.

\footnotetext{
1 Este artículo ha sido realizado en el marco del proyecto de investigación "Las peregrinaciones a Santiago de Compostela en la España de la segunda mitad del siglo XIX: entre tradición y modernidad en el contexto europeo" (MINECO, Programa Estatal de Fomento de la Investigación Científica y Técnica de Excelencia, Subprograma Estatal de Generación de Conocimiento, 2015/2017, HAR2014-58753-P). IP Antón M. Pazos.

2 Consejo Superior de Investigaciones Científicas, Instituto de Estudios Gallegos "Padre Sarmiento".

E-mail: rosario.valdes@iegps.csic.es
} 


\section{Introducción ${ }^{1}$}

La colección diplomática del monasterio de Santa María de Ferreira de Pallares (Guntín, Lugo) constata la existencia en pleno medioevo de un casal y un hospital llamados de Pena Godón que estaban dentro del coto de dicho monasterio en la heredad de Vilar de Couso, estratégicamente enclavados sobre la margen del Camino Francés (Fig. 1).

Tanto el casal como el hospital siguen sin estar considerados en la bibliografía jacobea que con carácter generalista trata la historia de la hospitalidad en las rutas jacobeas, y esto a pesar de que fueron dados a conocer por Regueira Vázquez (1999) en el único artículo que hasta la fecha se ha publicado sobre Pena Godón y también por Vázquez García (2008a) a través de una breve reseña contenida en la web
"Galicia Digital". Ferreira Priegue (1988), Rey Caiña (1983) y Pereira Martínez (2005) se acercan igualmente al tema aunque de manera tangencial, ofreciendo escuetas referencias de la heredad de Vilar de Couso y del propio hospital en el contexto de trabajos más amplios de muy diversa índole.

En realidad es muy poco lo que conocemos de los hospitales del tramo galaico del Camino Francés, que se documentan en los siglos del pleno medioevo y que se caracterizaban por estar enclavados en entidades menores de población inmersos en un ambiente plenamente rural. La casuística suma poco más de media docena ejemplos en los que la información se reduce -salvo algunas excepciones- a simples menciones que permiten como mucho constatar su existencia en esa época.

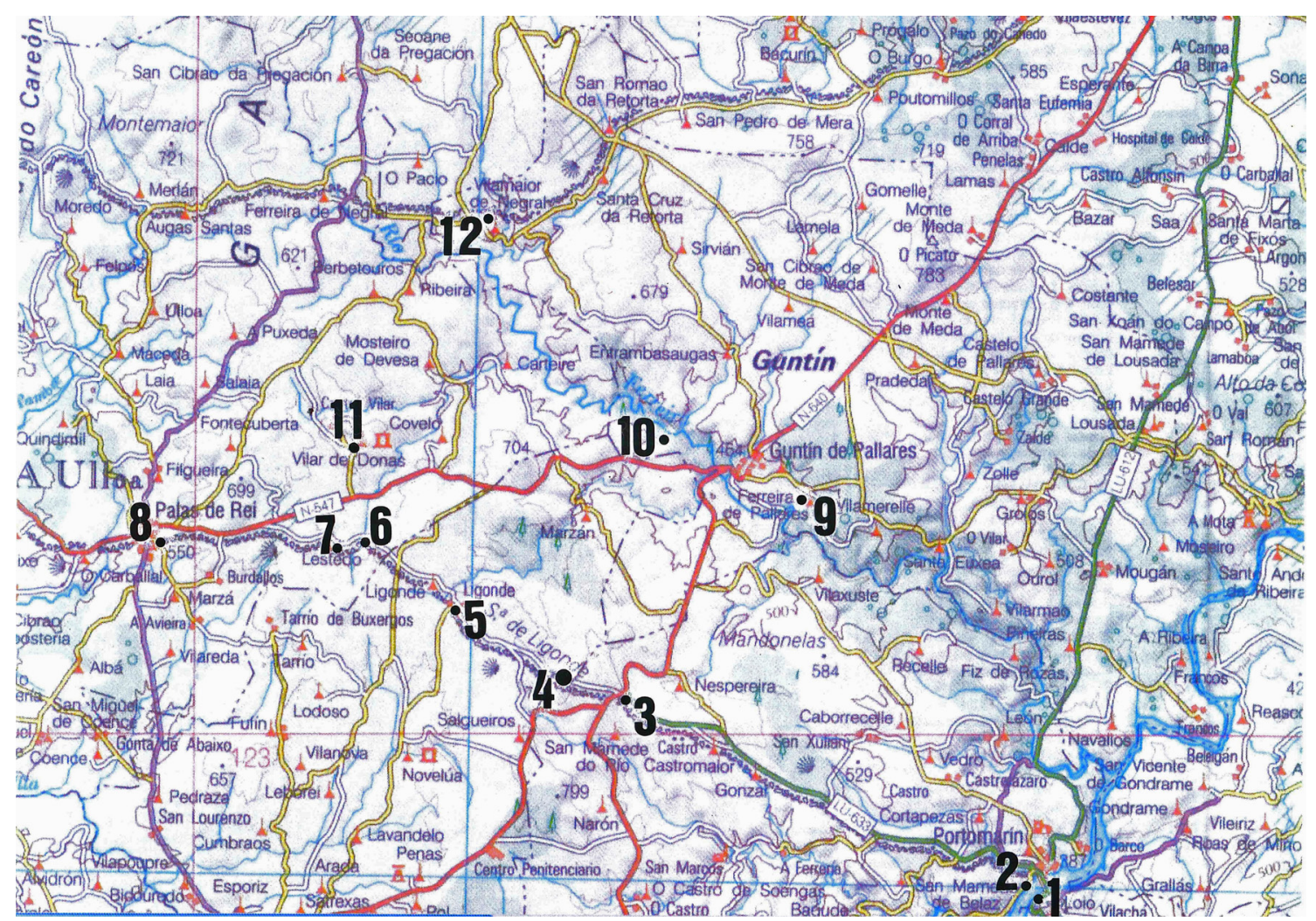

Fig. 1. Tramo del Camino Francés entre Portomarín y Palas de Rei ${ }^{4}$

Abreviaturas utilizadas en este artículo: AGS (Archivo General de Simancas), (CE) Catastro de la Ensenada, (RG) Respuestas Generales. AHN (Archivo Histórico Nacional), SCSR (Sección Clero-Secular-Regular).

4 Deputación Provincial de Lugo (2009): Mapa da rede viaria de la provincia de Lugo. Escala: 1:200.000. (Cartografía (C) Instituto Geográfico Nacional). 1. Hospital de San Pedro de Portomarín. 2. Hospital de la Encomienda de San Xoán de Portomarín. 3. Hospital de la Cruz. 4. Hospital de Pena Godón. 5. Hospital de Ligonde. 6. Hospital de Portos. 7. Hospital de Lestedo. 8. Palas de Rei. 9. Hospital y enfermería de Ferreira de Pallares. 10. Encomienda de San Fiz do Hermo. 11. Enfermería y hospedería de Vilar de Donas. 12. Hospital de Vilamaior de Negral. 
Creemos que Pena Godón constituye el caso paradigmático y escasamente conocido de un lugar ligado a la tierra, cuya evolución no se explica si no tenemos en cuenta la propia historia del monasterio que poseyó el casal y su hospital. Así la documentación de Ferreira de Pallares nos permite asomarnos siquiera a una historia que está determinada por la gestión de las explotaciones agrarias de las que provenían todos los recursos, por el reparto de la propiedad que confería el poder y por las relaciones sociales en las que intervinieron eclesiásticos, nobles y campesinos. Es esta una senda de doble sentido y si bien es cierto que resulta ineludible contextualizar Pena Godón en un ámbito más amplio para llegar a su comprensión, creemos también que los estudios sobre áreas reducidas como la que aquí tratamos constituyen la base necesaria que permite comprobar y contrastar las líneas de la evolución histórica general.

\section{Pena Godón en el tramo del Camino Francés de Portomarín a Palas de Rei (Lugo)}

El casal de Pena Godón, denominado más tarde como "lugar de la Magdalena", se mantuvo habitado cuando menos desde la plena Edad Media hasta la Edad Moderna, constituyendo hoy en día un despoblado del que tan solo se conservan algunos restos que permanecen soterrados y ocultos bajo la espesa vegetación que invade el monte recientemente reforestado, circunstancia que de momento impide que una prospección meramente superficial aporte resultados significativos (Fig. 2). Aún así los vecinos del lugar cercano de Ventas de Narón mantienen recuerdo vivo del antiguo asentamiento y lo sitúan en las inmediaciones de la llamada "Pena da Madalena" o "Pena do Convento"; con este último nombre y también como "Monte da Señorita" y "Fonte Madanela" aparece reseñado en calidad de yacimiento arqueológico en los planos anexos al decreto de delimitación del Camino Francés, promulgado por la Consellería de Cultura y Turismo de la Xunta de Galicia (2011: 36597). Por su parte Regueira Vázquez (1999: 135) publica la fotografía de dos piezas de cantería provenientes de este lugar, una de ellas es una dovela decorada con un motivo ajedrezado muy semejante a las que componen las arquivoltas de las portadas románicas de ciertas iglesias emplazadas en la misma comarca.

El yacimiento se localiza sobre el cordal montañoso de la sierra de Ligonde, al pie del pico que sobrepasa los 750 metros de altitud, por donde hoy transcurre el Camino Francés (Fig. 3) en el tramo que media entre las poblaciones principales de Portomarín y Palas de Rei, en la provincia de Lugo; el enclave -que está dominado por la peña del monte que daba nombre al lugar- se encuentra próximo al núcleo de población de Couso (Santiago de Ligonde, Monterroso), sobre la divisoria del término municipal con Portomarín, en pleno corazón de Galicia (Fig. 4).

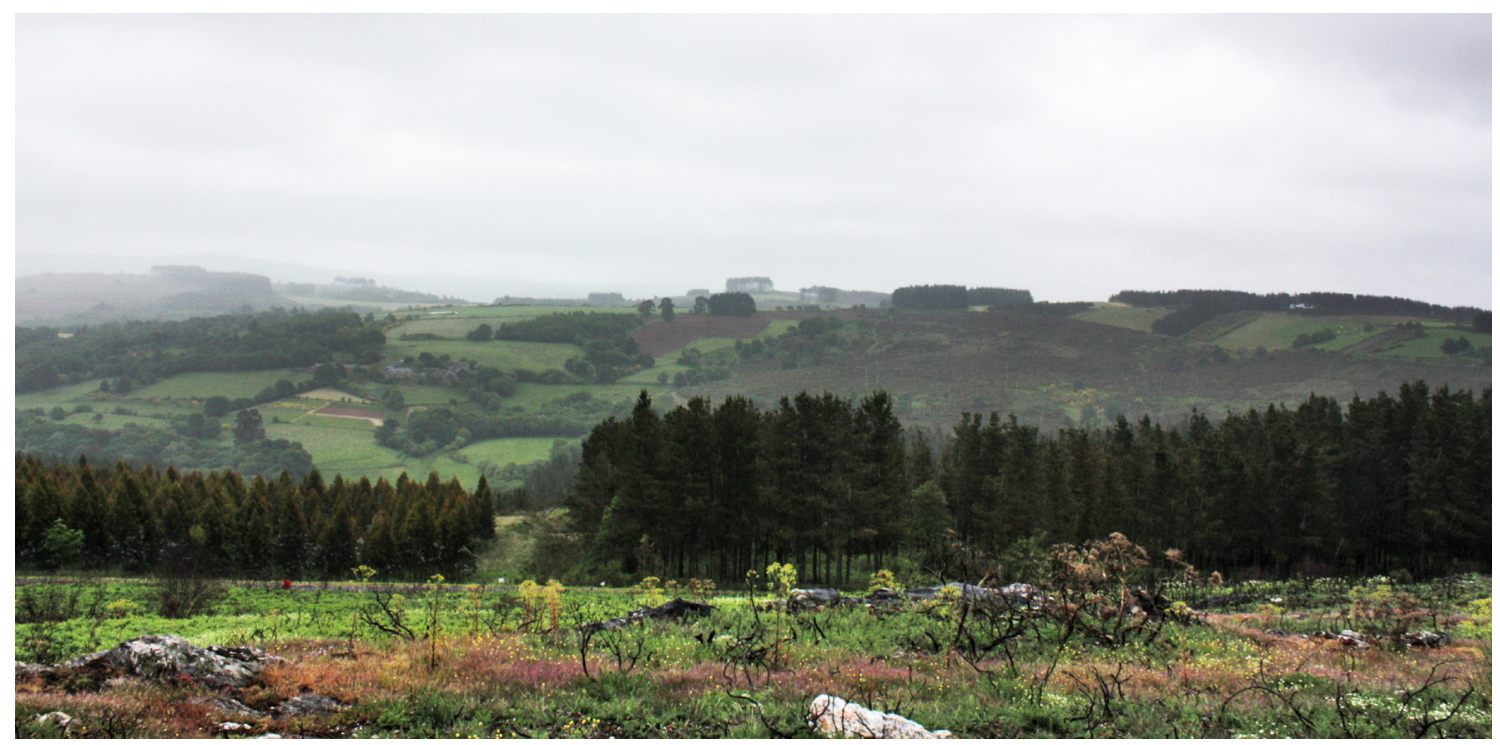

Fig. 2. Emplazamiento del despoblado de Pena Godón (sobre la línea de árboles). En la ladera de enfrente el lugar de Couso 


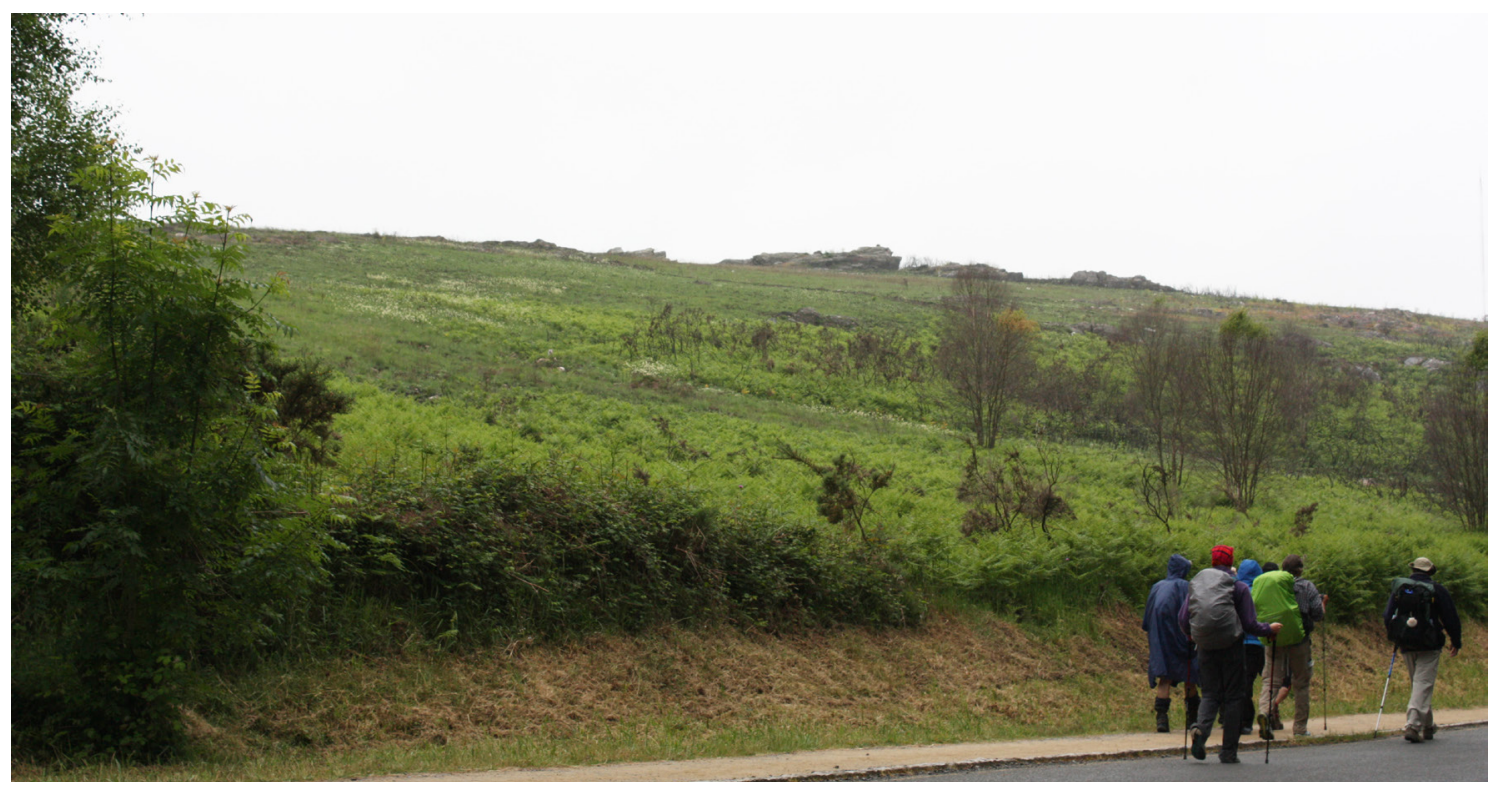

Fig. 3. Alto de Pena Godón visto desde el emplazamiento del despoblado y del Camino Francés

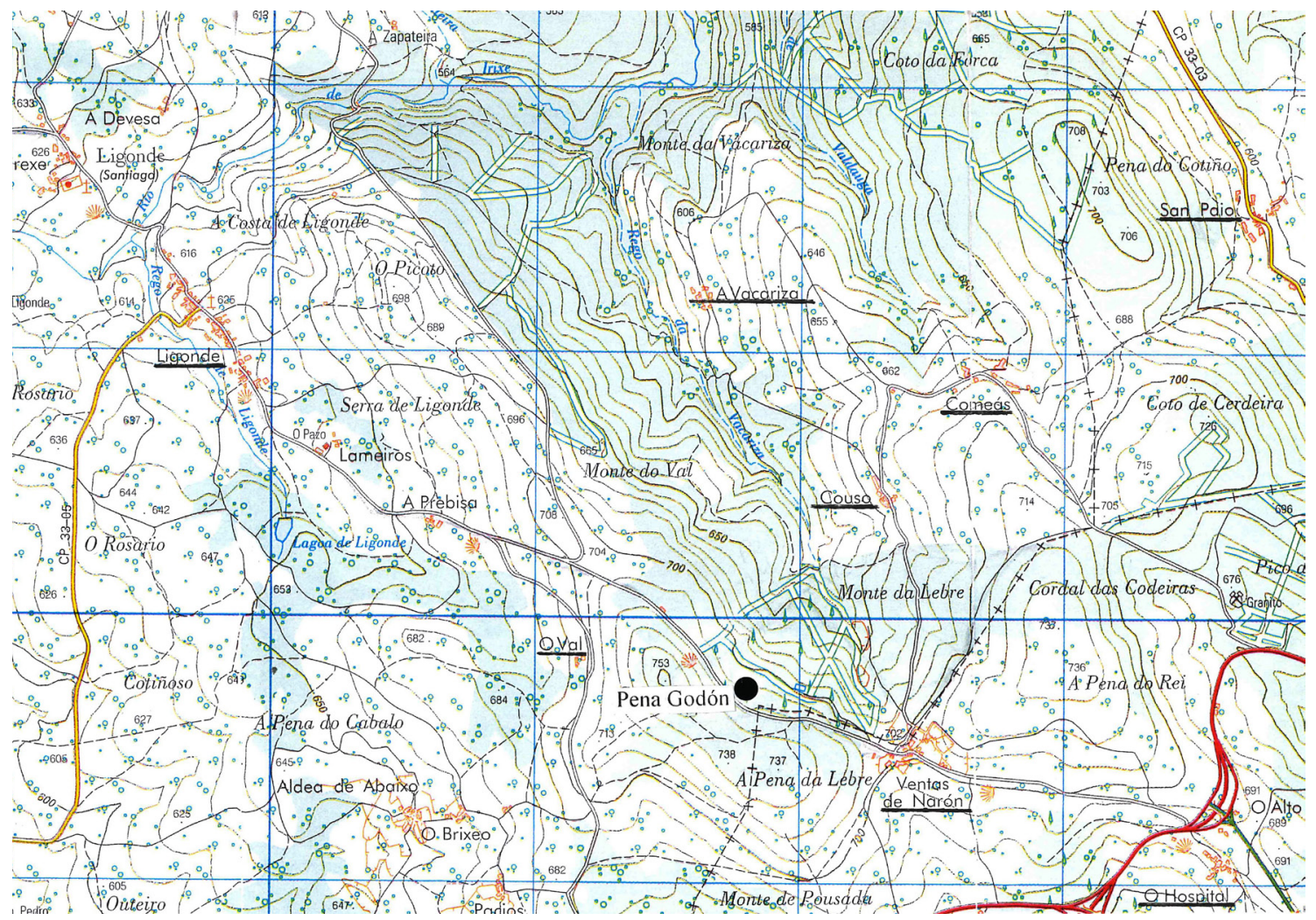

Fig. 4. Localización del despoblado medieval de Pena Godón, en las proximidades del lugar de Couso, parroquia de Santiago de Ligonde, ayuntamiento de Monterroso (Lugo) ${ }^{5}$ 
Sin ser de los peores, era un tramo duro del Camino que por momentos atravesaba ásperos y solitarios parajes en los que se hacía imprescindible la asistencia hospitalaria. En esta zona la población se fue asentando en pequeñas entidades concentradas y relativamente distanciadas unas de otras, que coexisten todavía al lado de casales dispersos que se reparten entre las explotaciones agropecuarias (Lois González 1993: 367-373, Valcárcel Díaz 1993: 9293); casi todas esas entidades agrupan sus viviendas en torno a las iglesias cuya existencia se documenta desde la Edad Media.

De los peligros que entrañaban estos pagos para los peregrinos de entonces se habla en el Códice Calixtino que en su libro primero advierte:

Las meretrices que (...) entre Puerto Marín y Palas de Rey, en lugares montuosos, suelen salir al encuentro de los peregrinos, no sólo deben ser excomulgadas, sino que además deben ser despojadas, presas y avergonzadas, cortándoles las narices, exponiéndolas a la vergüenza pública. (Moralejo Laso, Torres Rodríguez y Feo García 1992: 21).

La sierra sobre la que estuvo emplazado el lugar de Pena Godón constituye una divisoria natural entre las cuencas de los ríos Miño y Ulla. Desde Portomarín situado a orillas del Miño había (antes de la construcción del embalse de Belesar) un desnivel de casi 500 metros que se salvaban en apenas doce kilómetros de constante subida hasta llegar a la cima de Pena Godón, a partir de ahí el Camino sigue otros tantos kilómetros por el cordal montañoso atravesando la parroquia de Ligonde, para efectuar a continuación un descenso más suave desde Lestedo hacia Palas.

Los monjes de Ferreira de Pallares tenían su monasterio en la vertiente de la sierra que cae hacia el Miño, extendiéndose los términos de su coto por el lado sur hasta el Camino Francés, siendo la Pena Godón uno de los hitos que señalaban los límites de la demarcación. En pleno medioevo el coto monástico lindaba por el sudeste con los dominios de la encomienda de Portomarín de la orden militar de San Juan de Jerusalén, mientras que por el oeste colindaba con el coto de San Fiz do Hermo (Santiago de Entrambasaugas, Guntín) que era de los templarios ${ }^{6}$. A su vez, el coto de San Fiz lindaba -también por el occidente- con el coto del monasterio de Vilar de Donas (San Salvador de Vilar de Donas, Palas de Rei) perteneciente a la orden de Santiago ${ }^{7}$.

Cuando en el siglo XIII los benedictinos de Pallares asumieron la labor de asistir a los peregrinos del Camino Francés en el hospital de Pena Godón, los sanjuanistas -que debían tener ya la jurisdicción de Portomarín en virtud de las donaciones reales- se habrían hecho cargo del hospital del burgo de San Nicolás que había sido edificado en tiempos de la reina Urraca a comienzos del siglo XII ${ }^{8}$, mientras que por su parte los santiaguistas tenían una enfermería en Vilar de Donas, construyendo más tarde una hospedería en este mismo convento (Novo Cazón 1986: 176, 234) .

6 En 1311 Fernando IV donó al obispo Juan de Lugo la tierra de Pallares (donde se encontraba el coto de Ferreira) por los siguientes términos: "Primeramente como se departe por un cabo por la tierra del hospital de los freyres de Sant Johan que es cerca de Portomarin, et otrosi por el coto de Sant Fiz do Hermo de la orden del temple, et dende como se ayunta al vuestro coto de Lugo" (Portela Silva 2007: 139).

El monasterio de Vilar de Donas tuvo jurisdicción en múltiples lugares, propiedades y heredades dentro de los términos de los concejos de "la feligresía de San Cristóbal de Lestedo" (atravesada de parte a parte por el Camino Francés) y de la vecina "tierra de la Repostería" (que integraba la parroquia de Palas de Rei) cuyos pobladores habían recibido del rey Alfonso IX fueros municipales (Novo Cazón 1986: 168-169, Arcaz Pozo 1994: 360-362, 676).

8 Véase López Ferreiro (1901: 306), Vázquez Seijas (1945: 28-30), Vázquez de Parga, Lacarra y Uría Ríu (1948: 336-337), Arcaz Pozo (1995: 258-259), Recuero Astray, González Vázquez y Romero Portilla (1998: 17), Barquero Goñi (1999: 94-95), García Tato (2004: 16, 28, 40 y 119-120). A mediados del siglo XVIII este hospital pervivía junto con el otro hospital de peregrinos que estaba en el burgo de San Pedro de Portomarín -situado en la orilla opuesta del río Miño- que carecía de rentas, mientras que el de los sanjuanistas estaba dotado con 16 ferrados de centeno, medio "cañado" de vino, 4 carros de leña, 2 carros de paja y 1 ferrado de castañas verdes con las que se mantenían a los pobres (AGS, CE, RG, libro 183, fols. 12782v, 12798v).

9 Los santiaguistas tuvieron en el lugar de Portos (Santiago de Lestedo, Palas de Rei) un hospital junto al Camino que no sabemos cuando se construyó; en el año 1469 lo aforaron junto con el propio lugar de Portos con la obligación de su cuidado y mejora y la prohibición de enajenarlo (Novo Cazón 1986: 426). En 1494 este hospital estaba muy deteriorado y sin servicio de hospitalero. Según se dice en el Libro de Visitas del monasterio correspondiente a ese año, el responsable de la situación de su abandono era el conde de Monterrei Sancho de Ulloa, que ocupó el coto del monasterio por vía de encomienda imponiendo su propio "espitalero", al que había tratado "como a basallo" (Arcaz Pozo 1994: 463, 517). 


\section{La heredad de Vilar de Couso}

El monasterio de Ferreira de Pallares fue fundado por los condes Ero y Elvira. En el año 898 la condesa Elvira donó a dicho monasterio la tercera parte de Vilar de Couso, siendo los dos tercios restantes para los pobres; la donación incluía la tercera parte del ganado vacuno y cabrío para el monasterio, además de la totalidad de la cabaña porcina (Rey Caiña 1985: 275) ${ }^{10}$.

El monasterio se mantuvo por largo tiempo bajo el patrocinio de los descendientes de los condes fundadores. Así en el documento que recoge la genealogía del conde Ero se dice que el conde Rodrigo Muniz y su hermana Elvira con su marido, Pay Gómez de Carrión:

meteron orden en este moestero de Ferrera de San Beyto et testaron allos monges o moestiro cum suas herdades et cum seu couto et cum suas criazones. Et del conde don Rodrigo Muniz nascio a condessa dona Maior Rodriguez, et esta dona Maior Rodriguez pidió a enperador que coutasse aquel couto aos monjes que era sua heredade. $(\text { ibid. } 808)^{11}$

Lo cierto es que en el año 1129 el rey Alfonso VII donó a la susodicha Maior Rodríguez y a la comunidad de Pallares el coto del monasterio de Ferreira por los términos especificados en el correspondiente diploma, que por lo que respecta al entorno del lugar del que hablamos iban por el camino de "Coderas", por las "mamoam Golpeleras" y por la dehesa de "Causso a Penam Godom" y de allí por el "caminum francorum" hasta el "Castrum Maioren" (Portomarín, Lugo) 12 (AHN, SCSR, carpeta 1082 , N. 8). Esta donación fue confirmada por Alfonso XI en 1342 y por Juan I en 1380 (ibid. 1112-1113).

\subsection{El casal y el hospital medieval de Pena Godón}

En el año 1241 el monasterio de Ferreira de Pallares se encontraba en pleito con los templarios del coto vecino de San Fiz do Hermo a causa de la heredad de Vilar de Couso, siendo nombrados en ese momento los procuradores que iban a representar a los monjes de Ferreira frente al comendador Juan López del coto de San Fiz (ibid. 402) ${ }^{13}$. El pleito se prolongó en las siguientes décadas, tiempo en el que se sostuvo una larga disputa por la propiedad del lugar y hospital de Pena Godón en la que tuvieron la oportunidad de pronunciarse los testigos presentados por las dos partes.

De las declaraciones contenidas en el interrogatorio del pleito (ibid. 803-807, 814-822) se desprende que los monjes de Ferreira tenían determinados derechos y propiedades en la heredad de Vilar de Couso que les habrían sido dadas -según unos- por la condesa Elvira y -según otros- por ciertas condesas que habían morado en aquel lugar ${ }^{14}$. Sea como fuere,

10 Sostienen Pallares Méndez y Portela Silva (1975: 108-109) que a partir de la segunda mitad del siglo X el término "villar" alude a una explotación agraria independiente, que resultaba de la fragmentación de las antiguas "villas" de cuyo conjunto se desgajaron las tierras de las zonas marginales que se iban ganando a bosques y baldíos; no obstante, ellos mismos señalan que en el caso de las menciones anteriores a esa época "villar" aparece como sinónimo de "villa".

11 Esta última señora, también llamada Mayor Guntroda Rodríguez, estuvo casada con Fernando Núñez, hijo del conde Nuño Menéndez; tuvieron por única hija a la condesa Fronilde, casada a su vez con el conde Rodrigo Pérez de Traba, hijo del segundo matrimonio del conde Pedro Froilaz, ayo de Alfonso VII (Salazar Acha 1989: 76-77, Torres Sevilla 1999: 125).

12 La demarcación dejaba fuera del coto de Ferreira la vaguada formada por el arroyo que hoy se llama de Vacariza, donde se emplaza el propio lugar de Couso.

13 No fue este el único enfrentamiento que a lo largo del siglo XIII mantuvo el monasterio con la encomienda; los cotos de ambas instituciones eran limítrofes y se daba el caso de que tanto los templarios tenían posesiones en los términos de Ferreira, como los benedictinos en los de San Fiz do Hermo. Esta situación dio lugar a sucesivas disputas por las distintas demarcaciones y por la interferencia de los unos en numerosas iglesias, lugares y heredades de los otros. El primer pleito se produjo en el año 1227 , planteándose otros contenciosos -además del que nos ocupa- en los años 1229, 1241 y 1265 (Rey Caiña 1983: 96-97, 100, 108, 113; Martínez Díez 1993: 75, Pereira Martínez: 128-130).

14 Cuando en el pleito se habla de las condesas o de la condesa Elvira no sabemos con certeza a qué señoras se están refiriendo. Pudiera tratarse de la fundadora del monasterio de Ferreira de Pallares o de sus supuestas descendientes Elvira Muñiz y su sobrina la condesa Mayor Guntroda Rodríguez; no obstante estarían muy alejadas en el tiempo, ya que un testigo asegura que su padre había sido nutritus (ayo) de la susodicha Elvira. Más próximas a la época en que se entabló pleito estarían la condesa Fronilde y su hija Guiomar. La primera de ellas fue también patrocinadora del monasterio femenino de Ferreira de Pantón (en tierra de Lemos) que lo donó a la orden del Císter en 1175 (Manrique 1649: 28-29, Risco 1798: 31-33). Curiosamente existe una vieja tradición que atribuye la fundación del monasterio de Vilar de Donas a dos "dueñas" (de ahí su nombre), llamándose una de ellas Elvira, de quien Álvarez Carballido (1909: 61) dice que sería de la familia de los Arias de Monterroso. No hay que olvidar que los monasterios de fundación familiar eran lugar de acogida y retiro de las mujeres de la estirpe, tanto de las solteras que esperaban cumplir con los pactos matrimoniales, como de las que se quedaban viudas (véase García de Cortázar 2004: 223). 
al parecer al monasterio le correspondía la parte de la heredad que comprendía el monte y la dehesa de Couso "del prado arriba", dividiendo por la "Pena de Vaca" y por la "Fonte Pedosa" de tal manera que "contra la cima" era de Ferreira y "en el fondo" -hacia el valle- pertenecía a otros particulares que son nombrados simplemente como los "erderos" o "herderos de Monterroso"; por su condición de tales herederos es muy posible que fuesen descendientes de los condes fundadores del monasterio ${ }^{15}$.

Los testigos del pleito nombran a dos personajes destacados (probablemente hermanos) como avaladores de la causa del abad Abril de Ferreira (1222-1231), uno de ellos era Rodrigo Arias del que se dice que era hijo de Arias Pérez; el otro era Fernando Arias que -en boca de un monje del monasterio- se revela como propietario dentro de la heredad y que en su calidad de comendador instó al mismo Abril de la siguiente manera: "poblar esos vilares nuestros de tras lo montem [de Couso] ante que nos hic faciatis pesar" (ibid. 816).

Figura en el mismo interrogatorio un noble llamado Fernando Muñiz que aparece ejerciendo en la heredad de Vilar de Couso ciertos derechos y prerrogativas propias de un señor de la tierra. Por la época a la que se remontan los testigos, por la coincidencia del nombre y por el papel que desempeña, podría ser identificado como el mismo Fernando Muñiz de Rodeiro relacionado al final de la genealogía del conde Ero - citada más arriba- donde se dice que era hijo de Munio Fernández de Rodeiro (mayordomo real de León en 1188) y nieto del conde Munio Peláez (Salazar Acha 1989: 83, Pardo de Guevara y Valdés 2006: 266); sería también el "tenente de Pallares y del coto de Ferreira" que con el mismo nombre aparece -entre otros grandes señores- rubricando un documento de la colección diplomática del monasterio fechado en el año $1219^{16}$.

De Fernando Muñiz dicen los testigos que acotó el monte de Couso por desafecto a Ligonde (cuyos términos eran colindantes). $\mathrm{Su}$ mayordomo Domingo Pérez, que tenía "decretos" otorgados por él, mantenía pignorados en la susodicha heredad la explotación de los campos de labranza, los ganados y las forestas, cobrando por ello determinadas rentas. Al parecer hubo quejas de los hombres de Ligonde por el derecho o "caritel" que Domingo Pérez ostentaba en el monte de Couso sin que nadie supiese muy bien por quién, aunque algunos decían que por "voz" de Ferreira; fue entonces que Fernando Muñiz ordenó a Domingo Pérez "alzar aquel caritel". El mismo magnate mandó a María Cortesa que fuese a poblar Vilar de Couso.

La repoblación de Vilar de Couso, lo mismo que la del lugar vecino de San Paio, fue igualmente contemplada por el abad Juan Ibáñez (1204-1222) y también -como ya hemos visto- por su sucesor el abad Abril. Se daba la especial circunstancia de que en los mismos pagos estaba anteriormente establecido un "mourum", decían unos que por los frailes y otros que por los condes o por la condesa; quiso éste trabajar en la heredad sobre el Camino y no le dejaron. El término con que se alude a este poblador indica un origen racial referido en los diplomas de la época a los que eran musulmanes, o de origen musulmán; la razón de que se encontrase aquí es que hubiera podido ser traído en régimen de esclavitud ${ }^{17}$. En relación con esto último y con la condición de los moradores del coto de Ferreira cabe reseñar que en la concordia suscrita en 1227 por

15 Señala García de Cortázar (2004: 228-231) que en la Edad Media se consideraban "herederos" o "diviseros" a los miembros de las parentelas que unidos por vínculos de legítima consanguinidad componían la descendencia familiar de los fundadores de centros monásticos, en los que tenían derechos de propiedad a través de sus "porciones" o "partes" reconocidas, estando excluida cualquier posibilidad de fragmentación del cenobio. Como tales herederos escogían al abad y delegaban en él la administración de los bienes que la parentela entregaba al monasterio. Para evitar los efectos perniciosos que la pluralidad de herederos pudiera tener se llegó a centralizar la tutela de los monasterios familiares en manos de un solo "dominus", escogido entre los parientes que ofreciesen mayores garantías de buen hacer.

16 Fernando Muñiz aparece igualmente desempeñando los cargos de "tenente" de Pallares y también de Monterroso en otros documentos de Ferreira fechados entre los años 1204 y 1227. Asimismo consta que en 1223 Fernando Muñiz y su mujer Teresa Rodríguez donaron al monasterio de Santa María de Ferreira de Pallares un solar y una casa llamada del hospital, sita en el burgo de Vilanova de Negral sobre el Camino de Oviedo, ahora conocido como Camino Primitivo de Santiago. Las condiciones de la donación establecían que los monjes debían acoger en este hospital a pobres y peregrinos dándoles fuego, agua, paños, paja y limosnas al servicio de Dios (Rey Caiña 1985: 312-315, 328, 333-334, 346); véase también Vázquez García (2008b).

17 Tal fue el caso de unos moriscos que a mediados del siglo XII llegaron al monasterio cisterciense de Santa María de Sobrado (A Coruña), después de haber sido comprados por los propios monjes en los mercados de Castilla y Portugal (González Paz 2004: 297-300). 
los templarios de Hermo y los benedictinos de Ferreira, se estableció que los abades no poblasen sus lugares de "monjes conversos" (que constituían la principal fuerza de trabajo dentro de los centros monásticos encargándose de las labores del campo), ni tampoco de "hombres privilegiados", sino de "rústicos" (Rey Caiña 1985: 343). Este afán repoblador debe entenderse en el marco de la expansión económica que entre los siglos X al XIII caracterizó Galicia (al igual que el conjunto del occidente cristiano) basado en el crecimiento demográfico, en el avance de las roturaciones y en el incremento del rendimiento de la tierra (Pallares Méndez y Portela Silva 1982: 96-104).

La heredad de Vilar de Couso se extendía entonces hasta el "Caminun Sancti Iacobi" y dentro de sus términos había diversos casales estando uno de ellos en un sitio del monte de Couso llamado de Pena Godón, ubicado sobre el propio límite con el Camino, figurando Ramiro Muñiz y Rodrigo Torto como dos de sus moradores ${ }^{18}$. En el mismo lugar confluía la demarcación de otra heredad perteneciente a los templarios de la encomienda de San Fiz do Hermo que se extendía hasta "Porto do Val" (sobre el lugar actual de O Val, en la parroquia de Santiago de Ligonde); los llamados a declarar por parte de la encomienda templaria hablaban del "monte de San Félix" refiriéndose al mismo monte que por la vertiente contraria miraba a Vilar de Couso.

El caso es que Pedro Eanes construyó en tiempos del deán de Lugo Juan Arias ${ }^{19}$ la casa de un hospital en Pena Godón, sin que estuviese muy claro a quién correspondía la titularidad del solar: si a la encomienda de San Fiz do Hermo o al monasterio de Ferreira.

Es así que aseguró un testigo que hacía unos cincuenta años que Ramiro de Pena Godón dijo saber que Pedro Eanes quiso poner un hospital bajo el Camino y que entonces vino el comendador Munio y no permitió hacer nada porque dijo que era su heredad (Rey Caiña 1985: 814).

Otros testificaron que el hospital era por "derecho" de Ferreira, lo mismo que la heredad en que estaba; uno de ellos oyó decir del hospital de Pena Godón que por ser la heredad de Ferreira, el propio Pedro Eanes devolvió lo que había debajo del Camino (ibid. 803).

Asimismo en otro punto del interrogatorio, un clérigo de Ferreira y un hombre más del coto del monasterio declararon que cuando alguien fue a decirle al deán Juan Arias que se estaba construyendo la casa del hospital bajo el Camino, respondió que no lo quería porque la heredad era de Ferreira (ibid. 815).

En el mismo pleito se habla también del hospitalero que tenía paciendo sus cabras en el monte de la heredad de Vilar de Couso, pagando por ello cinco sueldos a Domingo Pérez. También se menciona la existencia de una vaqueriza en la misma heredad que según unos fue de la condesa Elvira, de la que se decía que moró en el cercano lugar de Vilariño (igualmente desaparecido); según otros esta misma vaqueriza era por "derecho" del monasterio de Ferreira, de manera que uno de sus frailes llevaba la leche al Camino para darla por amor de Dios: "pro dare pro Deo" (ibid. 816).

Desconocemos cuál fue la resolución de este contencioso, pero sí sabemos que a partir de entonces y de forma progresiva los monjes de Ferreira fueron incrementando sus propiedades en la heredad de Vilar de Couso, haciéndose cuando menos con una parte de la propiedad del hospital de Pena Godón.

Así en el año 1265 el abad Munio Páez de Ferreira dio a Vasco Fernández "miles de

18 Según Pallares Méndez y Portela Silva (1975: 110-112), el término “casal” se refiere por lo general a explotaciones dependientes que estaban integradas en otras explotaciones más amplias formando parte de ellas como un elemento más; se caracterizaban por la presencia de la casa y por la existencia de unas tierras cultivadas, ocupadas y explotadas por un terrazguero y su familia a cambio del pago de un censo.

19 Este deán consignó junto al obispo Rodrigo II de Lugo un documento fechado en 1187 por el que la condesa Fronilda hizo una importante donación al monasterio de Ferreira de Pallares; desde esta fecha y hasta el año 1213, figura de nuevo como deán de Lugo en otros documentos de la propia sede obispal y también de los monasterios de San Julián de Samos y Vilar de Donas. En 1194 donó el monasterio de Vilar de Donas a la orden de Santiago, realizando la cesión junto con sus hermanos y herederos, entre los que figuran los hijos de los hermanos Fernando, Rodrigo y Nuño Suárez; en el documento correspondiente consta que el deán Juan Arias era hijo de Arias Pérez de Monterroso, fundador del susodicho monasterio. En 1153 "Arias Petri Montisrosi" aparece corroborando una carta de donación que el conde Fernando Pérez y su hermano Bermudo (hijos del conde de Traba, Pedro Froilaz) hicieron a favor del monasterio de Santa María de Sobrado. Véanse Risco (1798: 346, 350), García Conde (1991: 210), Rey Caiña (1985: 386), Lucas Álvarez (1986: 147), Novo Cazón (1986: 199, 201, 203, 204), Loscertales de García de Valdeavellano (1976: 34). 
sancta Ougea" y a su mujer Urraca Martínez el casal de San Juan de Novelúa (parroquia de San Cristobo de Novelúa, Monterroso) con todas sus pertenencias, a cambio de su quiñón del hospital de Pena Godón y del casal de Recelle de Mariz (San Pedro de Recelle, Portomarín) que había sido de su padre Fernando Arias y de su abuelo Arias Pérez, además de su heredamiento de Pivas (también en San Pedro de Recelle) y el pago de 130 sueldos (ibid. 582) ${ }^{20}$.

La adquisición del hospital vino a acrecentar la labor asistencial desarrollada por los monjes benedictinos de Pallares, que antes de finalizar el siglo debían mantener además de este establecimiento el hospital de Vilanova do Negral (que como ya hemos visto, les fue donado por Pedro Muñiz en 1223), y también el hospital que tenían en la propia casa del convento junto con una enfermería ${ }^{21}$.

En el inventario de los bienes del monasterio de Ferreira fechado en el año 1287 figura:

In Pena Godom herdamento de don Vasco Fernandez, quanto y avia per su cabeza et de mays herdamento de don Fernan d'Arias Testa Fardia que nos der in cambio por Nuvelua et quinum de Gonzalo Fernandez que compro o abbade don Monio et herdamento de Maria Perez et Lucia Perez, su hermana (ibid. 743).

Como vemos en la relación se incluye la heredad de Vasco Fernández, aunque esta vez sin hacer referencia al hospital de Pena Godón del que no volvemos a encontrar noticias.
Con el paso del tiempo los benedictinos de Ferreira de Pallares aumentaron sus dominios tendiendo a concentrar las propiedades. De este modo al término de la Edad Media no solo habían logrado hacerse con nuevas porciones en Pena Godón, que en esos momentos había cambiado su denominación apareciendo en los documentos como lugar de la Magdalena, sino también con el propio Casal de Couso que fue aforado por los monjes acogiéndose a un modelo de explotación indirecta de la propiedad característico de los dominios gallegos de la baja Edad Media, que ofrecía la gran ventaja de asimilar la condición de los foreros a la de los habitantes de los cotos al convertirlos en vasallos, sumando el señorío jurisdiccional al territorial.

Así en un documento del año 1424 figura que Inés Pérez, moradora de Lama en la feligresía de San Pedro de Recelle, donó al monasterio de Santa María de Ferreira de Pallares todas las heredades que le pertenecían "no lugar chamado da Madalena do camyno frances". Se especifica que el lugar de la Madalena y sus heredades se dividían en dos mitades, una mitad pertenecía a Ferreira, mientras que la otra mitad estaba dividida a su vez en otras ocho partes; de estas ocho partes una era igualmente de Ferreira y otras tres pertenecían a Inés Pérez que eran las que donaba en este momento (ibid. 1173) ${ }^{22}$.

Poco después - concretamente en 1438-nos encontramos con que el Casal de Couso sito "su a Madallena do Camino Francés que e no

20 El propio Rey Caiña habla de un "Hospital de Nespereira" basándose en este único documento, donde figura claramente: "espital de Pena Godonit” y no de otro nombre (Rey Caiña 1983: 102). A unos dos kilómetros de distancia de Pena Godón delimitando por la propia vía jacobea con el coto de Nespereira, se encontraba el lugar del Hospital de la Cruz (San Mamede do Río, Portomarín) donde sí hubo un establecimiento hospitalario referido por Pascual Madoz (1850: 433), quien dice que se ignoraba el paradero de los bienes y rentas del hospital de la Cruz, al igual que ocurría con el de Portomarín (sin especificar cuál), Ligonde, Lestedo y otros que la Junta Municipal de Beneficencia de Lugo solicitó se descubriesen y agregasen al de la Caridad de aquella capital provincial, lo que fue concedido por Real Orden del 12 de marzo de 1835. Los hospitales de la Cruz y Lestedo debían estar desmantelados de mucho tiempo atrás, puesto que en el Catastro de la Ensenada se dice que no había ninguno dentro de los términos de sus respectivas feligresías (AGS, CE, RG, libro 178, fol. 8002r y libro 185, fol. 13681v).

21 Sabemos del hospital del convento gracias al testamento del clérigo Juan Domínguez fechado en el año 1278, por el que entre otras mandas dejó al monasterio de Pallares ocho sueldos para la "pitanza do Espital" (Rey Caiña 1985: 689). Las noticias de la enfermería son anteriores remontándose al año 1231, momento en que el obispo de Lugo Miguel visitó la comunidad haciendo de mediador entre el abad y los monjes en la distribución de la hacienda monástica. El documento que recoge la visita nos muestra un monasterio regido por un sistema organizativo basado en las "ovenzas", unidades administrativas de base territorial o funcional, que eran gestionadas por distintos miembros de la comunidad (véase Andrade Cernadas 1992: 279). Con este sistema el abad dejaba de ser el único administrador del monasterio, tal como ocurría en épocas anteriores. En el susodicho documento se menciona la "ovenza" de la enfermería, que el obispo encuentra extremadamente pobre y endeble, decretando en consecuencia que fuese dotada con un "casal de Guntín con el cuarto de esa misma villa" (Rey Caiña 1985: 365).

22 En relación con el dominio monástico de Vilar de Donas señala Novo Cazón (1986: 93) que el uso del término "lugar" se generaliza a partir de la segunda mitad del siglo XV, lo que parece obedecer a una restructuración de los bienes del monasterio de tal manera que las parcelas que fueron adquiridas a lo largo de los siglos XIII, XIV y primeros del XV se agruparon en los "lugares" que eran unidades mayores destinadas al aforamiento. 
Couto de Ferreyra" estaba plenamente en manos del monasterio de Ferreira, que lo aforó ese mismo año estipulando en las condiciones del contrato que tanto Roy Gómez de Marzán, como su mujer Aldara Gómez y las otras personas a las que se aforó el Casal de Couso debían ser vasallos obedientes del monasterio de Ferreira y no podían vender, ni "sub-pignorar" sin permiso del abad; además debían labrar las heredades, mantener las casas y morar en ellas, pagando tres fanegas de cereal anuales limpias de polvo y paja y el décimo de lo que "Dios de en dicho lugar", y por razón de servicio debían entregar por Navidad capones y vino y por San Juan una olla de manteca o seis maravedíes por ella (ibid. 1224).

\subsection{Evolución posterior y abandono final: el lugar de la Magdalena en la Edad Moderna}

A comienzos de la Edad Moderna la reforma de las órdenes religiosas promovida por los Reyes Católicos supuso la agrupación de los monasterios benedictinos de Galicia bajo la autoridad de Congregación de la Observancia de San Benito de Valladolid, convirtiéndose el monasterio de Ferreira de Pallares en priorato del monasterio de San Julián de Samos; la anexión se produjo en el año 1517 en virtud de la bula Pastoralis officcii del papa León X (Arias Cuenllas 1992: 198-200). Al parecer el monasterio de Pallares se hallaba por entonces prácticamente carente de efectivos. Con todo los benedictinos conservaron sus dominios en el entorno de Pena Godón al menos hasta el siglo XVIII, manteniendo las tierras en régimen de explotación indirecta.

En 1549 para tomar posesión de la jurisdicción de Ferreira de Pallares el monasterio de Samos se ocupó de dejar bien establecidos los límites de la correspondiente demarcación, que por lo que respecta a la parte de la que venimos hablando continuaba estando establecida por Pena Godón y el Camino Francés, aunque integraba ya claramente la población de Couso (Vázquez da Pena 1967-68: 212-213).

En los apeos de bienes de Ferreira del año 1692 figuraban "los lugares da Madalena, Couso y casal de Vilariño", que estaban juntos y todo ello a término redondo en la jurisdicción de Ferreira, feligresía de Santiago de Ligonde; los traían Graciano y Francisco Martínez con sus consortes, ambos vecinos de Nespereira. La demarcación de estos lugares tenía su principio en el marco que se encontraba en el "Rego das Carballeiras" y de ahí al mojón que estaba pasando el portillo por donde se iba a la dehesa de Couso desde la casa en que vivía Gregorio de Bargados, morador del lugar de Couso; desde allí al marco sito en medio de dicha dehesa que dividía el lugar de Couso del lugar de la Magdalena y de ahí al marco que estaba debajo de la fuente "Verdella" y de ahí a la propia fuente, para continuar derecho al "Camino Francés" que iba por encima de la ermita de la Magdalena, por donde dividía la jurisdicción de Ferreira de las de la Ulloa y San Miguel das Penas, para continuar por el "Camino Francés aguas vertientes", hasta dar en "Pena Rey" y de ahí al "marco da mámoa de María de Recelle" y de ahí a cerrar en el mismo marco del "Rego das Carballeiras" que se citaba al comienzo de la demarcación (AHN, SCSR, libro 6512, fols. 507v, 508r).

Como vemos en este apeo se nombra la ermita de la Magdalena (Fig. 5), que muy probablemente fuese todo lo que quedase del antiguo establecimiento hospitalario ${ }^{23}$.

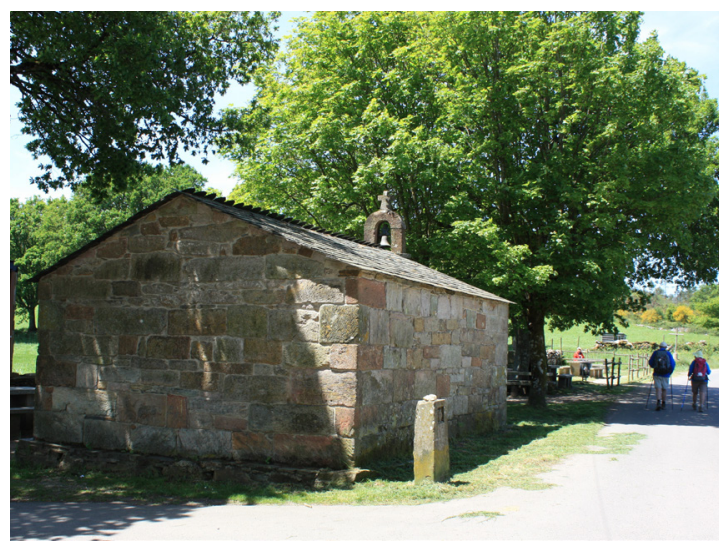

Fig. 5. Ermita de la Magdalena en su actual emplazamiento a la salida de Ventas de Narón

Finalmente en 1752 la "peña de Godón" y también el marco de la Madalena vuelven a aparecer en el Catastro de la Ensenada como

23 Los antiguos hospitales del Camino no solo ofrecían asistencia material, sino también auxilio espiritual. Otros hospitales gallegos del Camino que se encontraban bajo la advocación de la Magdalena eran los de Triacastela, el de la Encomienda de Portomarín y el de los agustinos de Arzúa. 
hitos delimitadores situados respectivamente en el extremo oriental del término parroquial de Santiago de Ligonde y en el extremo septentrional del coto de San Miguel das Penas, colindando con la feligresía de Santa María de Ferreira de Pallares. Consta en el mismo catastro que la feligresía de Ligonde era señorío del conde de Monterrei, excepto los lugares de Couso y Comeás que este poseían Andrés y Pedro García y aquel Gregorio Bragados y eran señorío del Real Monasterio de Samos, por cuyo título percibía el monasterio el derecho de luctuosa. Había en el término parroquial un hospital que era fundación de obra pía, cuya administración corría de cuenta del conde de Monterrei, en él se daba posada a los peregrinos, asistiéndoles con cama, luz y de comer y atenciones necesarias a los enfermos. Tenía de renta 1.500 reales de vellón al año ${ }^{24}$; de la feligresía de Santa María de Ferreira de Pallares se dice que no había hospital alguno (AGS, CE, RG, libro 174, fols. 5345rv, 5346r, $5353 \mathrm{v}$, libro 178 , fols. $8028 \mathrm{v}, 8038 \mathrm{rv}, 8048 \mathrm{v}$ y libro 185, fol. 13673r). Presumiblemente el hospital de Ligonde habría venido a sustituir al desaparecido establecimiento de Pena Godón, ya que ambos lugares se encontraban próximos entre sí.

La supresión de las jurisdicciones eclesiásticas privilegiadas en el siglo XIX, junto con el proceso desamortizador, fueron hechos que debieron incidir en el abandono definitivo del lugar de la Magdalena cuya ermita fue traslada al lugar de Ventas de Narón antes de que terminase la centuria.

\section{Conclusiones}

Aunque las noticias relativas al hospital de Pena Godón resultan ser escasas y estar fragmentadas en el tiempo permiten concluir que dicho establecimiento se construyó en el tránsito de los siglos XII al XIII, por iniciativa de Pedro Eanes que probablemente actuase por cuenta de la orden del Temple.

El hospital se levantó junto a un "casal" de la margen del Camino Francés sito en la heredad de Vilar de Couso, dentro de los términos de un "vilar" altomedieval del coto del monasterio de Ferreira de Pallares. El monte sobre el que se encontraba constituía una zona marginal del antiguo "vilar" dedicada a la explotación de los recursos ganaderos y forestales. En este punto colindaban los dominios de la encomienda templaria de San Fiz do Hermo y Ferreira de Pallares, circunstancia que propició un largo pleito por cuestión de la titularidad del propio hospital y del solar en que se emplazaba. Desconocemos cuál fue la resolución final del contencioso, no obstante si atendemos a las declaraciones de los testigos parece que Pedro Eanes se vio obligado a devolver a los de Ferreira lo que había construido en Pena Godón, tras las reclamaciones interpuestas por los benedictinos y por el comendador Munio y que aún en plena disputa, los monjes del monasterio debían llevar el establecimiento "por derecho", estando un hospitalero a cargo.

El expediente del pleito nos revela que la propiedad del monte de la heredad Vilar de Couso era un hecho colectivo, teniendo partes reconocidas -además de los monjes benedictinos- un grupo de laicos que se nombran simplemente como "herederos" o "herederos de Monterroso"; en virtud de tal condición cabe suponer que fuesen integrantes de la parentela de los condes fundadores del monasterio, a cuya estirpe pertenecía el que en 1219 figura como "tenente" del coto de Ferreira, Fernando Muñiz. Precisamente habrían sido unas condesas descendientes de la misma estirpe, quienes habrían dado al centro monástico "haber y voz" en Vilar de Couso; es decir les habrían dado la posesión de determinados bienes en la heredad y también derechos para disponer y administrar.

Conocemos por otra parte los nombres de algunos de los titulares que tuvieron porciones y parcelas en Pena Godón y que pudieran ser por tanto del grupo de los susodichos "herederos". Entre estos titulares -que terminaron por permutar o vender sus propiedades al monasterio- figura el caballero Vasco Fernández, que por ser "miles de sancta Ougea" pertenecía a la nobleza local, siendo de la familia de

24 El hospital de Ligonde se documenta al menos desde el año 1417 (Novo Cazón 1986: 332, 410, 412, Arcaz Pozo 1994: 461, 474, $517,581,824)$. Según Taboada Roca los hospitales de Ligonde y Leboreiro (este último en el ayuntamiento de Melide, A Coruña) fueron patronazgo de la casa de Ulloa; su administrador estaba autorizado para repartir las rentas sobrantes de ambas fundaciones entre los pobres del país. Al parecer en el año 1810 fue comisionado por la "Junta de Armamento y Defensa" José María Taboada y Santiso, dueño de la casa de Laia (Palas do Rei), para el secuestro de sus rentas (Taboada Roca 1933: 146). 
los Arias ya que consta que era nieto de Arias Pérez e hijo de Fernando Arias, el comendador aquel que en el pleito se atribuía la posesión de los "vilares" del monte de Couso; Vasco Fernández aparece en primera instancia como copropietario del hospital de Pena Godón, de manera que en 1265 intercambió el quiñón que ahí tenía con el abad Munio Páez de Ferreira.

Los primeros tiempos de la existencia de este establecimiento constituyen una etapa de expansión y máximo aprovechamiento de las tierras que se refleja en la repoblación del coto de Ferreira. Coinciden también con el afianzamiento de otros dominios situados en el mismo tramo del Camino Francés pertenecientes además de a la orden del Temple, a los caballeros de San Juan de Jerusalén y a los de la orden de Santiago, que desde el siglo XII y con apoyo de reyes y nobles se implantaron en Galicia comenzando a asumir la cobertura asistencial en el Camino; esto les permitió participar de las donaciones y limosnas que se entregaban para socorro de los peregrinos y de los caminantes pobres en general, beneficiándose a mayores de las exenciones fiscales que se pudieran conceder a tales efectos. Hasta entonces dicha cobertura -aún siendo los hospitales de fundación particular- había estado casi exclusivamente bajo el control de los monasterios. Los benedictinos se adaptaron a las nuevas circunstancias efectuando una profunda reforma de su propio sistema organizativo; es así que crearon "ovenzas" de carácter asistencial (dotadas con sus correspondientes rentas y atendidas por monjes especializados) que vinieron a cambiar la praxis hospitalaria en el seno de la orden.

En este contexto se explica el interés de los templarios por construir un nuevo hospital en Pena Godón y el afán de los abades de Ferreira por hacerse con él y no quedarse atrás, máxime en un lugar donde ya hacía tiempo que venían ejerciendo la caridad en favor de los viajeros necesitados.

Al término de la Edad Media la documentación nos permite comprobar cómo hubo un cambio en la denominación de las entidades de población, que parece estar relacionado con la trasformación del régimen de explotación de la propiedad y de su condición jurídica; de esta manera se vendrá a hablar del "lugar" y "casal" de Couso y también del "lugar" de la Magdalena (que no de Pena Godón, cuyo topónimo queda relegado a la peña del monte como mero hito delimitador), donde los monjes de Ferreira habían logrado concentrar un cierto número de parcelas que destinaron al aforamiento, convirtiendo lo que había sido de señorío laico en señorío monástico.

En el siglo XVII estos dos lugares, junto con el "casal" de Vilariño conformaron un "término redondo" que parece no existir a mediados del siglo XVIII, cuando en el Catastro de la Ensenada únicamente se mencionan los lugares de Couso y Comeás en la feligresía de Ligonde, que eran señorío del Real Monasterio de Samos.

La decadencia del monasterio de Ferreira de Pallares, convertido en priorato de Samos desde el comienzo de la Edad Moderna, pudo traer consigo el progresivo descuido de unas tierras, que ya de tiempo atrás se venían explotando de forma indirecta. Con todo, el despoblamiento y abandono definitivo de los antiguos lugares de la Magdalena y Vilariño habría que relacionarlo - sin duda- con la desaparición de los dominios monásticos tras la aplicación de las leyes de desamortización promulgadas en el siglo XIX.

\section{Referencias bibliográficas}

Álvarez Carballido, Eduardo (1909): "Monasterios olvidados. San Salvador de Vilar de Donas", Boletín de la Real Academia Gallega III/27, pp. 59-63.

Andrade Cernadas, José Manuel (1992): "El monasterio de Samos y la hospitalidad benedictina con el peregrino (siglos XI-XIII)", en H. Santiago-Otero (coord.), El Camino de Santiago, la hospitalidad monástica y las peregrinaciones. Salamanca: Junta de Castilla y León, Consejería de Cultura y Turismo, pp. 273-283.

Arcaz Pozo, Adrián (1994): Las ordenes militares en el reino de Galicia a fines de la edad media. Tesis doctoral. Madrid: Universidad Complutense.

— (1995): "Implantación y desarrollo territorial de la orden militar de San Juan de Jerusalén en Galicia (siglos XII-XV)", España Medieval 18, pp. 257-274.

Arias Cuenllas, Maximino (1992): Historia del monasterio de San Julián de Samos. Zamora: Ediciones Monte Casino. 
Barquero Goñi, Carlos (1999): "La Orden de San Juan en el Camino de Santiago: La Bailía de Portomarín (1158-1351)'”, Cuadernos de Historia Medieval (Sección Miscelánea) 2, pp. 89-117.

Conselleria de Cultura y Turismo (2011): "Decreto 227/2011, de 2 de diciembre, por el que se aprueba la delimitación de la ruta principal del Camino de Santiago, Camino Francés", Diario Oficial de Galicia 237, p. 36597.

Ferreira Priegue, Elisa (1988): Los caminos medievales de Galicia (Boletín Auriense, anexo 9). Ourense: Museo Arqueolóxico Provincial.

García de Cortázar, José Ángel (2004): "Monasterios hispanos en torno al año mil”, en Ante el milenario del reinado de Sancho el Mayor. Un rey navarro para España y Europa (Actas de la XXX Semana de Estudios Medievales de Estella. 14-18 julio de 2003). Pamplona: Gobierno de Navarra, pp. 213-269.

García Tato, Isidro (2004): Las encomiendas gallegas de la Orden Militar de San Juan de Jerusalén. Estudio y edición documental. Vol. 1. Santiago de Compostela: CSIC.

González Paz, Carlos Andrés (2004): "Sarracenos, moros, mudéjares y moriscos en la Galicia Medieval", Cuadernos de Estudios Gallegos 51/117, pp. 281-312.

Lois González, Rubén Camilo (1993): "Transformaciones Espaciales Recientes entre O Cebreiro y Compostela", en P. Torres Luna (ed.), Congreso Internacional de Geografia: Los Caminos de Santiago y el Territorio. Santiago de Compostela: Consellería de Relacións Institucionais e Portavoz do Goberno, pp. 361-383.

López Ferreiro, Antonio (1901): Historia de la S.A.M. Iglesia de Santiago de Compostela. Vol. 4. Santiago de Compostela: Seminario Conciliar Central.

Loscertales de García de Valdeavellano, Pilar (1976): Tumbo del monasterio de Sobrado de los Monjes. Vol. 2. Madrid: Dirección General de Patrimonio Artístico y Cultural.

Lucas Álvarez, Manuel (1986): El tumbo de San Julián de Samos. (Siglos VIII-XII). Santiago de Compostela: Publicaciones de la Obra Social Caixa Galicia.

Madoz, Pascual (1850): Diccionario Geográfico-Estadístico-Histórico de España y sus posesiones de Ultramar. Tomo 10. Madrid: Imp. del Diccionario.

Manrique, Angelo (1649): Cisterciensium seu verius ecclesiasticorum annalium a conditio cistercio. Tomo 3. Lugouni: Sumptitus Laurentis Anisson \& Soc.

Martínez Díez, Gonzalo (1993): Los templarios en la Corona de Castilla. Burgos: Editorial la Olmeda.

Moralejo Laso, Abelardo, Casimiro Torres Rodríguez y Julio Feo García (1992): Liber Sancti Jacobi. "Codex Calixtinus". Pontevedra: Xunta de Galicia.

Novo Cazón, José Luis (1986): El priorato santiaguista de Vilar de Donas en la Edad Media (1194-1500). A Coruña: Fundación "Pedro Barrié de la Maza".

Pallares Méndez, María del Carmen y Ermelindo Portela Silva (1975): “Aproximación al estudio de las explotaciones agrarias en Galicia en los siglos IX-XII", en Actas de las I Jornadas de Metodología Aplicada de las Ciencias Históricas. II Historia Medieval. Santiago de Compostela: Universidade, pp. 95-113.

— (1982): "Edad Media", en Historia de Galicia. Madrid: Editorial Alhambra, pp. 61-139.

Pardo de Guevara y Valdés, Eduardo (2006): "De las viejas estirpes a las nuevas hidalguías. El entramado nobiliario gallego al final de la Edad Media", Nalgures 3, pp. 263-278.

Pereira Martínez, Carlos (2005): "As relacións da orde do Temple con outras institucións", Anuario Brigantino 28, pp. 105-137.

Portela Silva, María José (2007): Documentos de la catedral de Lugo. Século XIV. Vol. 1. Santiago de Compostela: Consello da Cultura Galega.

Recuero Astray, Manuel, Marta González Vázquez y Paz Romero Portilla (1998): Documentos Medievales del Reino de Galicia: Alfonso VII (1116-1157). A Coruña: Xunta de Galicia.

Regueira Vázquez, Xosé (1999): "Ventas de Narón, Sala de la Reina y el Hospital de Pena Godón", Lucensia. Miscelánea de cultura e investigación 9/18, pp. 131-140.

Rey Caiña, José Angel (1983): "La abadía de Ferreira de Pallares desde 898 hasta 1300”, Cuadernos de Estudios Gallegos 34/99, pp. 89-115.

— (1985): Colección diplomática de Ferreira de Pallares. Tesis doctoral. Granada: Universidad.

Risco, Manuel (1798): España Sagrada. Tomo 41. Madrid: Oficina de la viuda e Hijo de Marín.

Salazar Acha, Jaime de (1989): "Los descendientes del conde Ero Fernández", El Museo de Pontevedra 43 , pp. 67-84. 
Taboada Roca, Antonio (1933): "Notas Históricas", en Terra de Melide. Santiago de Compostela: Seminario de Estudos Galegos, pp. 135-250.

Torres Sevilla, Margarita (1999): Linajes nobiliarios de León y Castilla. Siglos IX-XIII. Salamanca: Junta de Castilla y León.

Valcárcel Díaz, Marcos, Manuel Rodríguez Guitián, Antonio Martínez Cortizas y Augusto Pérez Alberti (1993): As Paisaxes do Camiño Francés en Galicia. Santiago de Compostela: Consellería de Relacións Institucionais e Portavoz do Goberno.

Vázquez García, Carlos (2008a): "Os hospitais de peregrinos do mosteiro de Ferreira de Pallares", Galicia Dixital $<\mathrm{http} / / /$ www.galiciadigital.com/opinion/opinion.2477.php>.

Vázquez García, Carlos (2008b): "Personaxes medievais das Terras de Pallares (V). Fernando Muñiz". Galicia Dixital <http://www.galiciadigital.com/opinion/opinion.2720.php>.

Vázquez de Parga, Luis, José María Lacarra y Juan Uría Ríu (1948): Las peregrinaciones a Santiago de Compostela. Vol. 2. Madrid: Consejo Superior de Investigaciones Científicas.

Vázquez da Pena, Marina (1967-68): "Documentos Históricos", Boletín de la Comisión Provincial de Monumentos Históricos y Artísticos de Lugo 8/67-70, pp. 212-213.

Vázquez Seijas, Manuel (1945): "En la ruta de los peregrinos. El Hospital de San Juan de Puertomarín", Boletín dela Comisión Provincial de Monumentos Históricos y Artísticos de Lugo 2/7, pp. 28-33. 